\title{
Leadership Styles and Entrepreneurial Orientation
}

\author{
Regina Ekiyor Edwin Dapper \\ Department of Business Administration and Management, Ken Saro-wiwa Polytechnic, Rivers State, Nigeria
}

\begin{abstract}
The style and form of leadership is critical to the organization's inclination and engagement in entrepreneurial activities and behaviour. This is as leadership styles offer either support and encouragement for entrepreneurial orientation or a stifling of innovativeness and pro-activeness through strict policies which emphasize conformity and unequivocal adherence to standards and norms. This paper is a critical review of leadership styles and their relationship with entrepreneurial orientation. The paper assessed five leadership styles - autocratic, democratic, laissez-faire, transactional and transformational leadership styles; and their impact on entrepreneurial orientation. The discourse revealed that the democratic and transformational leadership styles both share qualities and content which encourage and support entrepreneurial orientation characteristics such as aggressive competitiveness, innovativeness, pro-activeness, risk-taking and autonomy. The paper concluded that both leadership styles democratic and transformational leadership style; evidently support and enhance organization's capacity and tendency for entrepreneurial orientation.
\end{abstract}

Keywords: Entrepreneurial orientation, leadership style, autocratic, lasses-faire, democratic, transactional, transformational.

DOI: $10.7176 / \mathrm{EJBM} / 11-8-11$

Publication date:March $31^{\text {st }} 2019$

\section{Introduction}

The capacity of the organization to satisfy its market and clients is primarily a function of its ability to identify the underlying satisfaction gaps inherent within its market. This ability emanates from the organization's orientation towards entrepreneurial activities and behaviour such as innovativeness, risk-taking, pro-activeness and competitiveness. This view is shared by Baker and Sinkula (2009) who stated that entrepreneurial orientation goes beyond the routine functionality and transactions of the business to the practicalities of survival and sustained business performance. However, studies (Marturano \& Gosling, 2008; Chen \& Miller, 1994; Chen \& Hambrick, 1995) have consistently identified certain contextual as well as organizational factors as critical to the orientation of organizations, one of such factors is the leadership style of the organization (Mandell, 2003).

Literature (Yukl, 2010; Mandell, 2003) describes leadership as fundamental to the identification and successful implementation of strategies and long-term goals of the organization. In fact, Lewin (1998) notes that leadership is the core and pivoting unit of the organization. In this sense, the style of leadership would denote the level of support or constrain placed on the functions and orientations (e.g. entrepreneurial orientation) of the organization. Extant research (Bass, 1990; Lewin, 1998; Mandell, 2003; Yukl, 2010) offers both theoretical and empirical based models on the role of leadership and its effect on the entrepreneurial orientation of the organization; nonetheless, studies (Bass, 1990; Lewin, 1998) with precise focus on leadership styles have focused on identifying the differences and implications of such styles on followership and organizational performance - constructs quite distinct from entrepreneurial orientation.

This study critically reviews leadership styles - based on the models of Lewin (1998) and Bass (1990), and their impact on the entrepreneurial orientation. Given that both constructs (leadership styles and entrepreneurial orientation) are firm-level theories, the theories reviewed focused on the organization and the interactions therein by drawing from the leader-member exchange theory as its baseline theory. The significance of this paper is hinged on its attempt to identify the varied implications of various leadership styles on the behaviour of the organization and the extent to which they either support or delimit the entrepreneurial activities or behaviour of the organization.

\section{Leader-Member Exchange Theory}

The leader-member exchange theory describes and prescribes leader and subordinate relationships. It focuses on the dyadic features and exchanges between leaders and their followers or subordinates within the organization (Northouse, 2010). The key theme of the leader-member exchange theory borders on the issue of trust in the relationship between the parties and in this way, it addresses issues related to responsibility, in-groups and outgroups, member development and support within the organization. The leader-member exchange theory has over the years garnered strong support due to its focus on addressing transformational relationships within the workplace and its emphasis on quality exchanges and inter-dependence between parties and groups within the organization (Graen \& Uhl-Bien, 1996; Truckenbrodt, 2000).

Lunenburg (2010) opined that the key to leader effectiveness can be traced to the leader-member exchange theory's position on the identification on in-groups and out-groups. By in-groups he describes those individuals or 
members which are considered to be favoured and supported by the leadership, while out-group members are those considered as being low in terms of trust and confidence from the leader. The effectiveness of leadership is therefore based on its ability to harmonize the differences of these groups and to draw in out-group members through increased communication adequacy and participation. This would pave the way for improved workers behaviour and overall organizational effectiveness.

In the same vein, the leader-member exchange theory enhances the quality of innovativeness and pro-activity of the organization. By emphasizing on trust and inclusivity, members are allowed to be creative and innovative in their activities and roles. Graen and Uhl-Bien (1996) also highlight on the positive effect of trust and participative leadership in the transformation of relationships. According to them, relationships which are inclusive and supportive, have strong tendencies to generate behaviour such as citizenship, innovativeness and commitment. These enhance the organizations success rate and effectiveness. Graen and Uhl-Bien (1996) further note that leadership which is focused on growing and developing others, often supports risk-taking and substantial levels of pro-activity from subordinates. Workplace relationships characterized by such features, usually have an overt positive orientation towards organization change development, entrepreneurial behaviour and competition (Truckenbrodt, 2000).

By implication, the leader-member exchange theory identifies the relative behaviour and orientations of the organization as being connected or consequent of the behaviour and actions of its leadership. This implies that the styles of leadership would most evidently have varied effects and implications for the nature and quality of exchanges between leaders and their subordinates and as such, a deeper impact on the adoption or evidence of an entrepreneurial orientation by the organization. Going by this, it suffices then to say that the leader-member exchange theory not only prescribes appropriate leadership actions and styles but also points to the negative impact the misapplication of leader styles within settings or social frameworks not appropriate for it. The theory therefore offers this paper the required prescriptive and descriptive theoretical base in its critique of leadership styles and their implications for entrepreneurial orientation (Truckenbrodt, 2000; Graen \& Uhl-Bien, 1996).

\section{Leadership Styles}

In reviewing literature on leadership styles, this paper begins by offering a conceptual definition of leadership and its purpose. Leadership according to Yukl (2010), leadership is about influence and the ability to motivate or convince others to agree with and contribute towards identified goals or objectives, while Northouse (2010) described leadership as the ability to convince significant others to share in one's ideas or purpose. From the foregoing, three major functions and features of leadership are most evident: i) the identification of a purpose, aim, goal or objective, ii) the ability to influence others (which may be coercive, manipulative or persuasive, and iii) the sharing of ideals or what can be regarded as followership. As such, leadership implies the capacity to drive change or achieve goals through influence and followership.

By leadership styles, this paper refers to the forms, patterns or format through which the leader initiates or engages his or her followers or subordinates. Mullins (2000) described the leadership style as the manner or form in which the leader relates and influences the subordinates. It can also refer to the means through which the leader gets the job done or attains the desired goals or objectives of the organization. On the other hand, Howell and Costley (2006) asserted that leadership styles were often premised on the nature or context of the organization and most often such styles change or can be modified based on changes in the environment or even based on the social dynamics of the relationships within the organization. Although earlier scholars (Luthans, 1992; Tannenbanum and Schmidt, 1958) have tended to use both terms - leadership styles and leadership behaviour - synonymously implying that styles are linked to the behavioural dispositions or character of the leader, recent studies (Marturano \& Gosling, 2008; Kennedy, 2002; Mandell, 2003) have disputed this on the basis of the leader-member exchange theory which supports the evidence of choice and style modifications based on the fluidity of work relationships.

While the position on leadership styles as linked to behaviour obviously follow the trait theory of leadership (Carless, 1998; Luthans, 1992), theories such as that of the leader-member exchange offer a more hybrid approach to leadership which recognizes the leader's capacity to change alongside situations, contexts and even in line with expectations (Graen \& Uhl-Bien, 1996; Marturano \& Gosling, 2008). As such, the forms, styles and methods of leadership can be considered as tools or skills which can be changed or modified to suit the needs, goals or expectations of the organization. In this way, leadership styles describe the approach adopted by the leader in influencing, and ensuring that specific goals and objectives are achieved (Mandell, 2003; Mohammed and Hossein, 2006).

Subsequently, in assessing leadership styles, this paper as stated earlier, draws on the leadership style models of Lewin (1998) and Bass (1990). Thus, five leadership styles are identified as applicable within today's business work relationships - Autocratic, democratic, laissez-Faire, transformational and transactional leadership. These are described accordingly: 


\subsection{Autocratic Leadership Style}

This describes the form of leadership which is focused on command and obedience within the workplace. There is also a clear and obvious order of roles and hierarchy within the organization. Leaders within this capacity tend to be highly coercive and focus primarily on achieving the goals of the organization (Bass, 1990). Adebakin and Gbadamosi (1996) identify the autocratic leader as that individual who is highly conscious of his position as leader and who considers pay a just means for motivating the worker. Such leadership often displays low level of trust for subordinates and often utilizes threats or discipline as a means of keeping subordinates in line.

Although several studies (Santrock, 2007; Michael, 2010) have criticized and frequently viewed the autocratic leadership style as unhealthy and inapplicable in today's modern business context, it is however important to note that quite a few benefits or advantages accrue from this form or style of leadership. According to Lewin (1998), the autocratic leader is hardly distracted by other events or expectations inherent in work relationships other than attaining specified goals of the organization. The autocratic leader also has been recognized to be efficient and highly effective when it comes to timely goal delivery. Furthermore, autocratic leaders have been noted to have tight control and strong coordination over the affairs of the organization (Clark, Hartline \& Jones, 2007).

\subsection{Democratic Leadership Style}

The democratic leadership style describes that form of leadership that is participatory and inclusive. This form or style of leadership is focused on shared responsibilities, and subordinate recognition in the pursuit of goals or organizational objectives (Parker, 2003). Lewin (1998) in his study observed that workers under this form of leadership style were less productive in comparison with the autocratic style of leadership, nonetheless, the quality of their work was observed to be more substantial as they were offered more avenues for contributions and creativity under the guidance of the leader. This form of leadership allows for the generation of ideas, views and variety in perspectives with regards to tasks and role performance (Mullins, 2005).

It is a consultative form of leadership which incorporates the ideas and creativity of its workers or employees into its decisions. It is therefore high on its level of employer-employee correspondence and communication flow. However, despite its overall approval and commendation by scholars as appropriate and considerably effective, the democratic leadership has been argued to result in long decision-making processes, delays and in some cases, poor adherence to goal delivery timing. This is primarily due to the fact that power distribution and sharing is high and roles are often highly inter-dependent (Bell, 2013; Lewin, 1998).

\subsection{Laissez-Faire Leadership Style}

The laissez-Faire leadership style offers more freedom to the subordinates with low leadership presence or control. This form of leadership is considered by most scholars to be very weak and considered as a position in which the leader has little impact on the behaviour of the subordinates with regards to reward or the power to coerce (Lewin, 1998). In the same vein, Bass and Riggio (2006) describe the laissez-faire leadership as a destructive form of leadership which implies either a complete lack of control or the poor recognition and identification of workers with the leader. Yet still, this view appears to adopt extreme negative positions of the laissez-faire leadership style as some scholars have opted to view the laissez-faire from a more positive position; describing it as supportive of autonomy, work flexibility and highly effective given the evidence of freedom for the expression of employee expertise in their own fields or role performance (Goodnight, 2011; Chaudhry \& Javed, 2012).

\subsection{Transactional Leadership Style}

The transactional leadership style considers the relationship between the leader and follower as a transaction. The content and structure of the relationship between the parties is clearly defined and roles are accepted or recognized based on agreed forms of compensation and contribution. It is a relationship based on the exchange of reward (most especially in the form of pay or wages) contingent on the performance of specified roles or duties (Lyons \& Schneider 2009). The focus is primarily the achievement of stated goals and relationships are designed in such a way as to maintain standards and formats through the application of feedback measures and corrective tools, in the pursuit and actualization of such goals and objectives. Hence, the transactional leadership is often highly controlling and indicative of strict adherence to policies and articulated forms of work techniques and methods (Timothy et al, 2011; Shah \& Kamal, 2015).

\subsection{Transformational Leadership Style}

The transformational leadership style is considered a highly effective and rewarding style of leadership which offers benefits for both parties (leaders and followers). The premise of most scholars on transformational leadership style is that it encourages and supports the development of the subordinates through individualized consideration, intellectual stimulation, idealized influence and inspirational motivation. In the same vein, leaders stand to benefit from improved trust levels, loyalty and enhanced creativity of workers in the performance of their tasks (Cho \& Dansereau, 2010; Bushra et al. 2011). 
The transformational leadership style has been recognized as highly effective in garnering support and maintaining commitment from followership. Although, its focus involves not only the achievement of organizational goals but also the transforming of involved or engaged parties through the content of the relationships, it is highly recommended by numerous studies (Bushra et al. 2011; Aydin, Sarier, \& Uysal, 2013) primarily because of the evidence of healthy workplaces, employee wellbeing, innovation and a high level of trust between co-workers and between the leader and followers in the organization. There is also a congruence in studies that affirm that the transformational leadership style offers the organization a more substantial and positive outlook towards addressing its organizational change or development goals and objectives (Chu \& Lai, 2011; Behery, 2008; Aydin, et al, 2013).

\section{Entrepreneurial Orientation}

Entrepreneurial orientation describes the organizations willingness and desire to innovate and rejuvenate its services and products for improved quality and customer satisfaction. It is the organization's openness towards change and its tendencies for pro-activeness and risk-taking in achieving uniqueness and effectiveness in its service and market offerings (Baker \& Sinkula, 2009; Ibeh \& Young, 2001). As a firm-level construct, entrepreneurial orientation involves the organization's overall inclination towards innovation and its inherent capacities (skills, technologies and systems) with regards to achieving and sustaining such expectations or innovation goals.

Lumpkin and Dess (1996) offered a broad and well embraced definition of entrepreneurial orientation, stating that it comprised of actions, behaviour, structures, systems and processes which can be considered as reflecting aggressive competitiveness, pro-activeness, innovativeness, risk-taking and autonomy seeking. The basis of such orientation emanates from the organization's drive for survival, competitiveness and excellence in its service. Entrepreneurial orientation, being firm-level construct is however a function of several processes, exchanges and relationship formats within the organization which either support its manifestation or practices through various policies, structures and systems or mitigate its practices through various hinderances, levels of control and overall institutionalized aversion towards risk and change (Chen \& Miller, 1994; Chen \& Hambrick, 1995).

\section{Leadership Styles and Entrepreneurial Orientation}

The previous sections of this study addressed the concepts of interest - leadership styles, and entrepreneurial orientation. In this section, the paper discusses the relationship between leadership styles and entrepreneurial orientation. From the foregoing, it has been stated that leadership is imperative to the organization and that it implies the identification of goals, the influencing or motivation of subordinates and the evidence of followership. In the same vein, leadership style was described as the approach or format adopted by the leader in engaging and influencing the subordinates towards the achievement of organizational goals (Yukl, 2010; Northouse, 2010). This is as entrepreneurial orientation is considered as comprising of the aggressive competitiveness, pro-activeness, innovativeness, risk-taking and autonomy seeking behaviour of the organization, implying a tendency or inclination towards change receptivity and initiation (Lumpkin \& Dess, 1996).

Studies (Lumpkin \& Dess, 1996; Ibeh \& Young, 2001) reveal that the evidence or expression of entrepreneurial orientation by organizations is based on their behaviour and adoption of systems or policies, supportive of such orientation. Although the autocratic leadership style is noted as having a high productivity level result and timely delivery of goals and objectives, this form of leadership is noted to be constraining on creativity as workers are strait-jacketed into maintaining norms and following specific formats. Autonomy is also considered to be very low based on affirmations of high supervisory activities geared towards sustaining standards and formats (Lewin, 1998; Mandell, 2003).

One finds that the autocratic leader is best suited for routine organizational goal accomplishment and poorly suited for creative or inventive workplaces. On the contrary, the democratic leadership style which offers more levels of involvement and participation allows for more work discretion and creativity. Although the supervision is also substantial given the acknowledged levels of guidance and correspondence by leaders and supervisors, it however allows for a more focused alignment of such individual creativity and pro-activeness with the goals or values of the organization (Santrock, 2007; Clark et al, 2007).

Michael (2010) noted that the major set-back of the Laissez-faire leadership style is its apparent lack of cohesion and focus, given its often criticized lackadaisical leadership feature. In this way, while workers are allowed a high level of autonomy and a wide range of opportunities and space to be creative and bold in their work, there is a low level of cohesion and value alignment with majority of such creativity and talent wasted based on poor goal clarity, focus and shared values. This contrasts with the level of guidance offered by the democratic or participative leadership style which as noted offers a streamlining of values and ensures the appropriate application and utility of innovative practices and systems that best serve the organizations entrepreneurial goals and behaviour. This is also evident in the relationship between transformational leadership and entrepreneurial orientation as studies assert that there is a high evidence of innovation and pro-activeness given the content and developmental focus of the transformational leadership style (Bass, 1990). 
According to Bass (1990) the transformational leadership offers a more change and innovation-based content than the transactional leadership style. This is as the transformational leadership style adopts an orientation which not only pursues the overall organization goals, but also recognizes, supports and develops the talent, skills and creativity levels of the subordinates or employees; thus, supporting and encouraging organizational focus on satisfying market or client demands using unique and innovative processes, adopting and utilizing bold measures and techniques in the pursuit of goals and also maintaining high aggressive competitiveness in their market. This contrasts with the transactive nature of relationships and exchanges that occur under the transactive leadership style - driving primarily for the achievement of goals and objectives based on clearly stated employment or relational forms or statues which often mitigate against creativity, change or pro-activeness (Chu \& Lai, 2011; Behery, 2008; Aydin, et al, 2013).

Kurt Lewin's Model (Lewin, 1998)

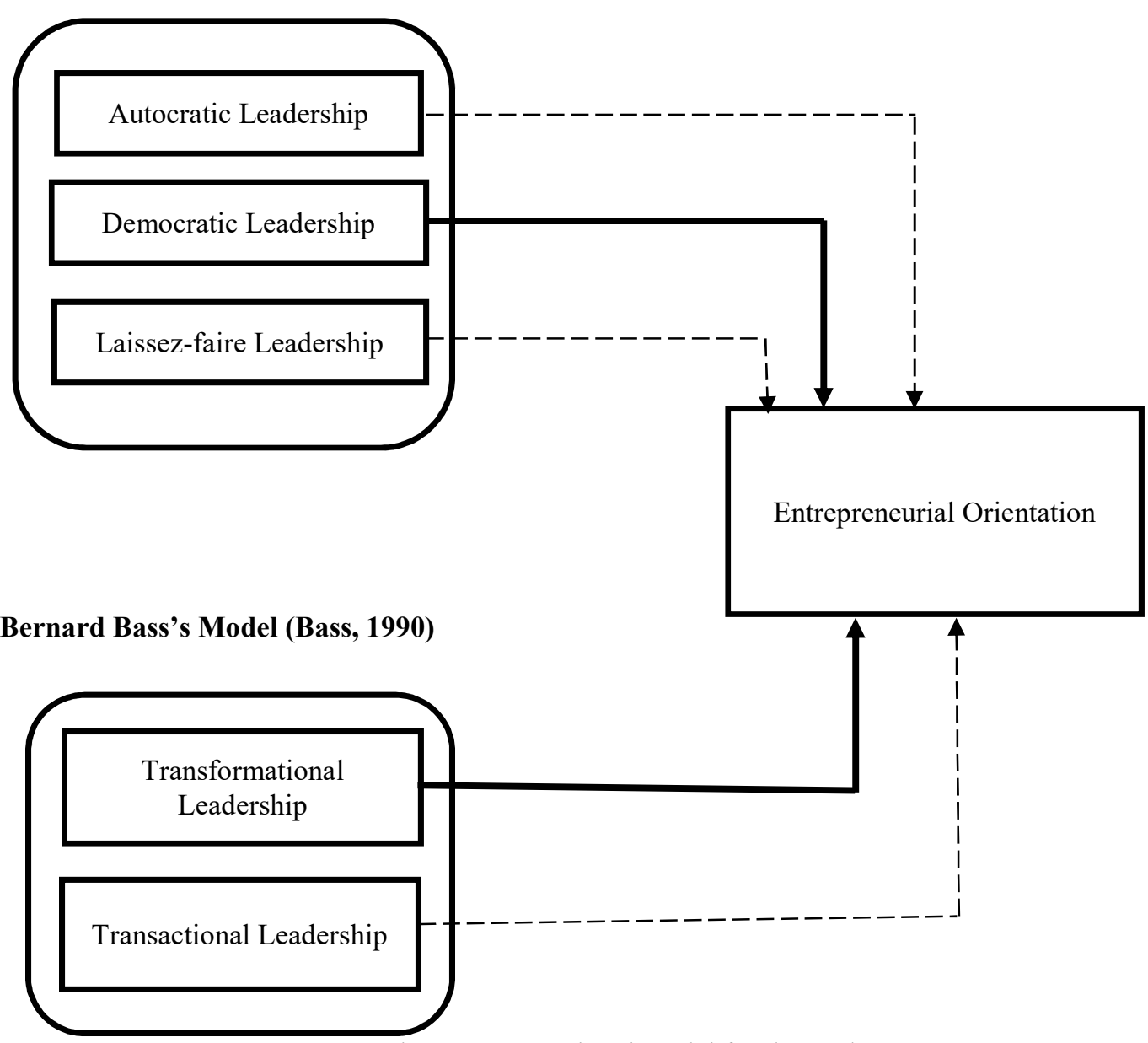

Figure 1: Operational model for the study

In view of the discourse and review of theoretical content bordering on the relationship between leadership styles and entrepreneurial orientation, this paper identifies the democratic leadership style of the Kurt Lewin's model (Lewin, 1998) and the transformational leadership style of the Bernard Bass's model (Bass, 1990) as the two most evident leadership styles with positive impact on entrepreneurial orientation. This position is illustrated in the operational model of figure 1 where both leadership styles are expressed as having stronger impacts (based on the bold lines) on entrepreneurial orientation.

\section{Conclusion}

The relationship between leadership styles and entrepreneurial orientation is such that identifies critical factors such as support, encouragement and sponsorship of innovation and creativity, work flexibility and autonomy as well as low supervision but evidence of clear expectations and guidance. The review revealed that although all five identified dimensions or forms of leadership style (autocratic, democratic, laissez-faire, transactive and transformational) all have certain qualities and features which may be of benefit to the organization, especially with regards to productivity and the quality of workplace relationships; it is however the democratic and transformational forms of leadership that are most impactful and supportive of entrepreneurial orientation. This is 
as these two forms not only identify and direct efforts towards goal achievement, but also incorporate workers through participatory and transformational leadership actions which allow for change in work formats, recognition for efforts, support of new ideas and substantial levels of flexibility and autonomy for pro-activeness and risktaking.

Subsequently, this paper concludes by stating that the styles of leadership each have varied forms of impact on the organization's inclination towards aggressive competitiveness, pro-activeness, innovativeness, risk-taking and autonomy seeking behaviour, however, it is the democratic and transformational leadership styles which most evidently support and enhance the organization's capacity and tendency for entrepreneurial orientation.

\section{References}

Adebakin O.I \& Gbadamusi E.A (1996). The practices of organizational leadership. Ibadan. Adeogun printing press.

Aydin, A., Sarier, Y., \& Uysal, S. (2013). The effect of school principals' leadership styles on teachers' organizational commitment and job satisfaction. Educational Sciences: Theory \& Practice, 13(2), 806811.

Bass B. M. (1990). Bass and Stogdill's handbook of leadership: theory research and managerial applications $3 \mathrm{rd}$ edition. NY: Free Press

Bass, B. M., \& Riggio, R. E. (2006). Transformational leadership (2nd ed.). Mahwah, NJ: Lawrence Erlbaum Associates.

Behery, M. (2008). Leadership behaviours that really count in an organization's performance in the Middle East. Journal of Leadership Studies, 2(2), 6-21.

Bell, R. M. (2013). Charismatic leadership case study with Ronald Reagan as exemplar. Emerging Leadership Journeys, 6(1), 66-74

Bushra, F., Usman, A. \& Naveed, A. (2011). Effect of transformational leadership on employees' job satisfaction and organizational commitment in banking sector of Lahore (Pakistan), International Journal of Business and Social Science, 2, (18): 261-267.

Carless, S. (1998). Gender difference in transformational leadership: an examination of superior, leader and subordinate perspective, Sex Roles, 39, 887-902.

Chaudhry, A. Q., \& Javed, H. (2012). Impact of transactional and laissez faire leadership style on motivation. International Journal of Business and Social Science, 3(7), 258-264.

Chen, M.J., \& Hambrick, D.C. (1995). Speed, stealth and selective attack: How small firms differ from large firms in competitive behaviour. Academy of Management Journal, 38: 453-482.

Chen, M.J., \& Miller, D. (1994). Competitive attack, retaliation and performance: An expectancy-valence framework. Strategic Management Journal, 15: 85-102.

Cho, J., \& Dansereau, F. (2010). Are transformational leaders fair? A multi-level study of transformational leadership, justice perceptions, and organizational citizenship behaviors. The Leadership Quarterly, 21(3) 409-421.

Chu, L., \& Lai, C. (2011). A research on the influence of leadership style and job characteristics on job performance among accountants of county and city government in Taiwan. Public Personnel Management, 40(2), 101-118.

Clark, R., Hartline, M., \& Jones, K. (2010). The effects of leadership style on hotel employee's commitment to service quality, Cornell Hospitality Quarterly, 50(2)

Goodnight, R. (2011). Laissez-faire leadership. Encyclopedia of Leadership. London, UK: Sage Publications.

Graen, G., \& Uhl-Bien, M. (1996). Relationship-based approach to leadership: Development of leader-member exchange (LMX) theory of leadership over 25 years: Applying a multi-level multi-domain perspective. The Leadership Quarterly, 6(2), 219-247.

Howell, J. \& Costley, D. (2006). Understanding behaviours for effective leadership, Pearson Prentice Hall, Upper Saddle River, NJ.

Ibeh K. \& Young S. (2001). Exporting as an entrepreneurial act: an empirical study of Nigerian firms. Europe. J. Market. 35(6):566-586.

Kennedy, J.C. (2002). Leadership in Malaysia: Traditional values, international outlook, Academy of Management Executives, 16,15-26

Lunenburg, F. (2010). Leader-member exchange theory: Another perspective on the leadership process. International Journal of Management, Business and Administration, 13(1), 1-5.

Luthans, F. (1992). Organisational behaviour. (9th ed). Singapore: McGraw Hill

Lyons, J. B., \& Schneider, T. R. (2009). The effects of leadership style on stress outcomes. Leadership Quarterly, 20, 737- 748 .

Mandell, B. (2003). A question about women and the leadership option, in Rhode, D. (Ed.), The difference difference makes, Stanford University Press, Stanford, CA.

Marturana A, Gosling J (2008). Leadership: The key concepts. London: Routledge Taylor and Francis Group. 
Michael. A. (2010). Leadership style and organizational impact. Retrieved from: http/ www.ala- apa.org.

Miller D (1983). The correlates of entrepreneurship in three types of firms. Manage. Sci. 29(7), 770-791.

Mohammad M, A., \& Hossein Y, M. (2006). A study of relationship between managers' leadership style and employees' job satisfaction. Leadership in Health Services, 19(2), 11-28.

Mullins .L. J, (2005). Management and organizational behaviour in Dolatabadi, R. H., \& Safa, M., (2010). The effect of directive and participative leadership style on employees' commitment to service quality, Euro Journals - International Bulletin of Business Administration.

Northouse, P.G., (2010). Public administration theory as discourse. Administrative Theory and Praxis, 15, $132-$ 139.

Parker, W. C. (2003). Teaching democracy: Unity and diversity in public life. New York: Teachers College Press.

Santrock, J. W. (2007). A topical approach to life-span development. New York, NY: McGraw-Hill

Shah, M., \& Kamal, H. (2015). Transactional leadership and job performance: An empirical investigation. Institute of Business Administration, 2 (2), 69-81.

Tannenbaum, R. \& Schmidt, W. (1958). How to choose a leadership pattern: Should a leader be democratic or autocratic - or something in between? Harvard Business Review, 37, 95-102.

Timothy C. \& Obiwuru (2011). Effect of leadership style on organizational performance: A survey of selected small-scale enterprises in Ikosi-Ketu council development area of Lagos State, Nigeria. Australian Journal of Business and Management Research, 1(7).

Truckenbrodt, Y. (2000). The relationship between leader-member exchange and commitment and organizational citizenship behaviour. Acquisition Review Quarterly, 5, 233-244.

Yukl, G. (2010). Leadership in organization. New York, University at Albani, State University of New York: Pearson. 